\title{
What is your duty of care?
}

\author{
Henrietta Hughes
}

\section{Introduction}

When there is a potential conflict between the duty of care to your patients, the health of a colleague and your career which do you put first? In the latest of our clinical conundrums a real-life scenario with this question was put to a counsellor, a general practitioner (GP), an ethicist and the General Medical Council (GMC).

\section{Clinical scenario}

You have just started in post with a single-handed GP. You like the work, the patient group and all the staff you work with. After a while, however, you begin to feel just a little uneasy following a number of remarks from patients: "The doctor did not listen", "I am not sure why the doctor prescribed this" and "I'd like a second opinion". You have also noticed in passing on a couple of occasions that repeat script requests seemed inappropriate: you felt unable to sign the prescriptions and thought medication reviews were needed. The reception staff chaperone the doctor and one of them remarks that her own doctor does breast examinations very differently: she tells you it was undertaken fully clothed. The next day a nurse speaks to you in confidence about a patient in whom she felt a diagnosis was missed. The patient is known to suffer anxiety, and was told her late period and abdominal pains were nothing to worry about. The following day she collapsed with an ectopic pregnancy. When you look at the consultation record there is only reference to her anxiety and no examination is recorded. You feel there are perhaps issues that need addressing. What will you do next?

\section{The panel}

Four professionals (detailed in Box 1) were invited to discuss what they would have done.

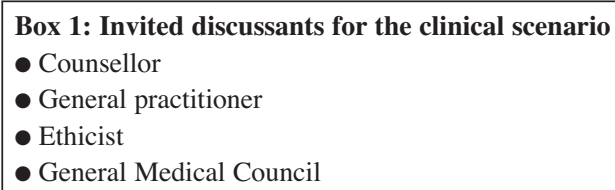

- General Medical Council

\section{Counsellor}

This conundrum needs to be considered from three angles. First, how to exercise your 'duty of care' and look after the interests of the patients. Second, how to attend to the GP who may be in a crisis. And third, how you safeguard your own position as a newcomer who wants to stay in the job.

There could be many reasons for the doctor's poor functioning: burnout, drinking, problems at home, divorce - the possibilities are many. If you get on well with the GP, initially an informal, direct approach is probably best. But before saying anything, do some preparation.

A wise move would be to check through patient records to see if the errors described are one-offs, or a disturbing pattern of bad performance through inappropriate prescribing or cutting corners in patient care. Make precise

J Fam Plann Reprod Health Care 2005; 31(3): 245-246

Solent Road Surgery, London, UK

Henrietta Hughes, MRGCP, DFFP, General Practitioner

Correspondence to: Dr Henrietta Hughes, Solent Road Surgery, 9 Solent Road, London NW6 1TP, UK.

E-mail: hen_and_mark@yahoo.com notes of things that have gone wrong to backup your case and to be able to challenge the GP in case of denial or argument. Choose a time when there are no patients around and a room where you can have a confidential discussion. Muster all your counselling skills and ask how the doctor is feeling. The GP may be relieved to be asked and open up readily to you. You can then discuss what to do. For example, the practicalities of taking a break from work and/or of re-allocating some tasks.

If you expect the doctor to be defensive and angry you may want to ask a senior colleague, whom you have briefed beforehand, to join the meeting. It's more difficult for a GP to sidestep two people. You also then have a witness of the meeting. Take notes summarising the discussion.

If this does not work, you can contact the GMC for further advice.

\section{General practitioner}

The situation needs to be dealt with sensitively as there is a potential threat to my relationship with my partner but there is also potential for me to fail in my duty as a doctor.

I have a responsibility to my patients to protect them from risk of harm posed by another doctor. I also have a responsibility as a doctor working in a team to respect the skills and contributions of my colleagues and be willing to deal openly and supportively with problems in the performance, conduct or health of team members.

I would want to gather as much information as possible. I would then try tactfully to raise the concerns with my colleague.

I would want to find out if my partner was having any physical, mental or family problems and if they were aware or concerned about anything to do with their performance. I would try to make this a learning experience for us both and try to implement ways we could enhance clinical skills, self-awareness and our ability openly to monitor our performance.

Systems exist externally to promote good practice in the form of appraisal. I would try to ensure internal systems within the practice were also set up so performance could be more openly monitored in the future.

If I felt my colleague were unresponsive to the concerns raised then I would be forced to speak with an appropriate person from the employing authority, such as the medical director or an officer of the Local Medical Committee (LMC). I would first seek advice from an impartial colleague and contact my defence body for advice.

Ethicist

One of the GMC's duties of a doctor is to "act quickly to protect patients from risk if you have good reason to believe that you or a colleague may not be fit to practise". Doctors have a professional duty to protect patients if they believe they're at risk and should act quickly in fulfilling this duty. However, the GMC does not tell doctors how to act. Neither does it explicitly say what sort of evidence would be required if there was a concern regarding a colleague's competence. It simply cites "good reason to believe" a colleague is unfit to practise as sufficient impetus for what has commonly become known as 'whistle-blowing'.

This lack of explicit guidance leaves huge latitude for deciding what constitutes "good reason to believe". This can be frustrating but does allow doctors to stay mostly 
within GMC guidelines however they finally decide to act (except, perhaps, in the most extreme and clear-cut cases of professional incompetence). The decision to whistle-blow is seldom, if ever, taken lightly, not least because of the potential impact on the future career of those who take this step.

As the doctor in this scenario you face an extremely difficult decision, and need to gather more facts in order to convince yourself you have sufficient evidence to justify taking action. Ideally you would speak to your colleague, but this may not be an option depending on your respective personalities. In reality you would more than likely have to use other techniques to check your facts in as tactful a way as possible. Perhaps suggesting to your colleague that the patient with the ectopic pregnancy has asked for a review of the case or, alternatively, setting up a system for patients to voice their concerns anonymously, or even instigating an audit to turn up the details of the case.

You would also want to be sure that your colleague's recent behaviour wasn't simply an aberration (has their partner just left them, for example?) before reporting them, and ideally would run the facts past a trusted and possibly more senior colleague before making your decision. If you decide you have to take action, there is always the option of making contact with the Primary Care Trust (PCT) rather than the GMC. The PCT may well refer their concerns about your colleague's fitness to practise onto the GMC, and though you would still be responsible for instigating the resulting investigation, you would not be the complainant.

No matter how many facts you collect, ultimately your decision to take action rests on personal values. What's more important, protecting patients or keeping you head down and getting on with your career?

\section{General Medical Council}

Good Medical Practice (GMP) makes it clear that you must protect patients from risk of harm posed by another doctor's conduct, performance or health. The safety of patients must come first at all times. Where there are serious concerns about a colleague's performance, health or conduct it is essential that steps be taken without delay to investigate the concerns to establish whether they are well founded, and to protect patients.

GMP sets out the steps that should be taken: "If you have grounds to believe that a doctor or other healthcare professional may be putting patients at risk, you must give an honest explanation of your concerns to an appropriate person from the employing authority, such as the medical director, nursing director or chief executive, or the director of public health, or an officer of your Local Medical Committee, following any procedures set by the employer. If there are no appropriate local systems, or local systems cannot resolve the problem, and you remain concerned about the safety of patients, you should inform the relevant regulatory body. If you are not sure what to do, discuss your concerns with an impartial colleague or contact your defence body, a professional organisation or the GMC for advice".
The senior GP may be putting patients at risk. As such, you must give an honest explanation of your concerns to the PCT or an officer of your LMC. The PCT will need to determine how it should investigate the concerns and whether to involve either the National Clinical Assessment Service or the GMC. If local systems cannot resolve the problem, and you remain concerned about the safety of patients, you should inform the GMC directly.

Where concerns are being investigated, GMP makes it clear that you must co-operate fully with any formal inquiry into the treatment of a patient and with any relevant complaints procedure. You must give, to those who are entitled to ask for it, any relevant information in connection with an investigation into your colleague's conduct, performance or health.

We recognise, of course, that it is often very difficult for doctors to respond to concerns about the performance of a colleague, especially if it concerns a senior colleague. Another difficult judgement will be whether to inform the doctor of the action you are taking. GMP underlines the importance of always treating colleagues fairly and not undermining patients' trust in the care or treatment they receive, or in the judgement of those treating them, by making malicious or unfounded criticisms of colleagues. In this case, however, there do appear to be substantial grounds for investigating the senior GP's practice and you would be failing in your duties as a doctor if you did not take any action.

\section{Discussion}

All our respondents have identified the importance of putting the patient's needs first by tackling the situation and not merely turning a blind eye. Seeking assistance from a senior colleague or the LMC is also helpful as it is more difficult to sidestep two people, and it is helpful to have concerns considered by an impartial third party. The decision to become a whistle-blower may, however, have serious consequences for a future career, even if these are not overt. The respondents have suggested more subtle ways of highlighting the problem, such as instigating an audit or asking the patient to complain. It may be that only a small subset of your colleague's skill set is of concern. Robust systems of internal appraisal and critical incident reporting to promote best practice is a formative way of approaching this situation, which may be less threatening to all concerned.

\section{Acknowledgement}

The author would like to thank the panel members for their input. A listing of the individual panel members who have contributed to the Clinical Conundrum section of the Journal is published annually.

\begin{tabular}{l}
\hline USEFUL CONTACT DETAILS \\
Local Medical Committee \\
http://www.bma.org.uk/ap.nsf/Content/linksgeneral+practitioners? \\
OpenDocument\&Highlight=2,Imc \\
General Medical Council \\
Tel: 08453578001 . http://www.gmc-uk.org/ \\
Primary Care Trust \\
http://www.nhs.uk/england/authoritiestrusts/pct/list.aspx
\end{tabular}

\section{PEER REVIEWERS}

If you have a special interest in one or more of the topics covered by the Journal and have some time available to peer review occasional papers in your own area(s) of expertise then perhaps you might be interested in joining the Journal's team of peer reviewers? For further information please contact the Editor or the Journal Editorial Office (details on page 173). 